\title{
The efficacy and safety of omalizumab in refractory chronic spontaneous urticaria: real-life experience in Turkey
}

\author{
Isil Bulur ${ }^{1 凶}$, Emel Bulbul Baskan², Mustafa Ozdemir³, Ali Balevi³, Emek Kocatürk Göncü4, Ilknur Altunay5, Müzeyyen \\ Gönül ${ }^{6}$, Can Ergin, İlgen Ertam ${ }^{8}$, Hilal Kaya Erdoğan ${ }^{9}$, Muzaffer Bilgin ${ }^{10}$, Mustafa Teoman Erdem ${ }^{11}$
}

\begin{abstract}
Introduction: This study used real-world data to evaluate the effectiveness and reliability of omalizumab in treating recalcitrant chronic spontaneous urticaria in Turkish patients.

Methods: Study data were collected retrospectively from eight tertiary-care hospitals in Turkey. This study included 132 patients with chronic spontaneous urticaria that were resistant to $\mathrm{H}_{1}$ antihistamine treatment in a dose up to four times the licensed dose and were treated with $300 \mathrm{mg} /$ month of omalizumab for 6 months.

Results: The mean weekly urticarial activity score (UAS7) after omalizumab treatment improved significantly compared to the pretreatment score $(p<0.001)$. Treatment response was detected primarily in the 1 st and 2 nd months after treatment. No significant association was observed between omalizumab's treatment effectiveness and disease-related parameters or laboratory data. The mean dermatology life quality index was $23.12 \pm 6.15$ before treatment and decreased to $3.55 \pm 3.606$ months after treatment $(p<$ 0.001). No side effects were reported in $89.4 \%$ (118) of the patients.

Conclusion: This study showed that UAS7 decreased significantly and quality of life improved in omalizumab-treated patients. Moreover, treatment effectiveness was mainly observed in the first 2 months after treatment. However, no association was observed between omalizumab treatment effectiveness and disease-related parameters or laboratory data.
\end{abstract}

Keywords: chronic spontaneous urticaria, omalizumab, dermatology life quality, UAS7, side effects

Received: 8 January 2018 | Returned for modification: 11 April 2018 | Accepted: 26 June 2018

\section{Introduction}

Chronic urticaria is urticaria that persists for longer than 6 weeks. Chronic spontaneous urticaria (CSU) is diagnosed by excluding inducible chronic urticaria as a possible diagnosis using the EAACI/GA²LEN/EDF/WAO guidelines (1). Approximately twothirds of patients with chronic urticaria are CSU patients, and the incidence rate of CSU is between $0.5 \%$ and $1 \%$ worldwide (1). CSU reduces the quality of life of patients and is therefore an important health problem (2).

The first-line treatment of patients with CSU involves the use of non-sedative $\mathrm{H}_{1}$ antihistamines. The licensed dose of these drugs can be increased up to fourfold in non-responding patients. Systemic steroids can be used at any time in patients showing an exacerbation of urticaria. However, one-third of patients do not respond to $\mathrm{H}_{1}$ antihistamine treatment even when the standard dose is increased (3). Omalizumab, cyclosporine, and montelukast are suggested as a third-line treatment of patients with CSU that are resistant to the $\mathrm{H}_{1}$ antihistamine treatment (1).

Omalizumab is a recombinant humanized monoclonal antiIgE antibody that binds to circulating free IgE heavy chains and indirectly downregulates FceRI receptor expression on mast cells and basophils $(4,5)$. Clinical studies have shown the effectiveness of 150 and $300 \mathrm{mg} / \mathrm{month}$ omalizumab in patients with CSU (6). However, limited real-world data are available on the efficacy and safety of omalizumab. Therefore, this study evaluated the effec- tiveness and safety of omalizumab in Turkish patients with CSU that were resistant to second-line treatments.

\section{Methods}

This multicenter, retrospective study was carried out at eight tertiary care hospitals in Turkey and was approved by a local ethics committee. The study included patients that were diagnosed with CSU based on EAACI/GA²LEN/EDF/WAO guidelines, had a minimum disease duration of 6 months, did not respond to $\mathrm{H}_{1}$ antihistamine treatment in a dose up to four times the licensed dose, and used $300 \mathrm{mg} / \mathrm{month}$ omalizumab for 6 months. Demographic data, disease-related parameters, and antibody levels were recorded retrospectively from patient records. The disease-related parameters included: disease duration, concomitant angioedema, concomitant dermographism, concomitant non-steroidal antiinflammatory drug (NSAID) hypersensitivity, concomitant atopy (rhinitis, asthma, and dermatitis), autologous serum skin test (ASST) positivity, weekly urticarial activity score (UAS7), dermatology life quality index (DLQI), treatments administered before the omalizumab treatment, treatments administered concurrently with the omalizumab treatment, and side effects observed during the omalizumab treatment. Antibody levels were recorded for serum total IgE antibody, antinuclear antibody (ANA), antithyroglobulin (AntiT) antibody, and antithyroid peroxidase (AntiTPO). The threshold value for ANA positivity was set at ANA titers $>1: 160$. 
Patients that had been treated with a steroid for a minimum of 10 days and cyclosporin at a dose of 3 to $5 \mathrm{mg} / \mathrm{kg} /$ day for a minimum of 1 month were considered to have used those treatments.

\section{Disease duration}

Disease duration was divided into the following four categories for statistical evaluation: < 1 year; 1 year to < 5 years; 5 years to $<10$ years; and $\geq 10$ years.

\section{UAS7 evaluation}

The UAS7 was used to evaluate disease activity. Itching severity and urticarial plaque number were graded as follows: no itching $=0$, mild itching $=1$, moderate itching $=2$, and intense itching $=3$; no urticarial plaques $=0,1-20$ urticarial plaques $=2,20-50$ urticarial plaques $=3$, and $>50$ urticarial plaques $=4$. The sum of 7 days of UAS values provided the UAS7 value. UAS7 scores were evaluated weekly, and an average of the scores from 4 weeks was used as the mean $\mathrm{UAS}_{7}$ for each month. Based on the UAS7 values, patients were classified as having severe CSU (UAS7: 28-42), moderate CSU (UAS7: 16-27), mild CSU (UAS7: 7-15), and well-controlled CSU (UAS7: 0-6) (1). Significant disease improvement was defined as a UAS7 value of $<6$ after the omalizumab treatment (7). The UAS7 value before treatment and the mean UAS7 value each month after treatment were recorded to evaluate treatment response.

\section{Quality of life assessment}

DLQI scores were obtained at the beginning of the omalizumab treatment and 6 months after treatment to evaluate the quality of life of patients with CSU (8).

\section{Omalizumab administration}

Omalizumab injections were administered by experienced nurses at the tertiary-care hospitals. The patients were monitored for a potential anaphylactic reaction for two hours after administering each of the first three doses of omalizumab and for 30 minutes after administering subsequent doses.

\section{Statistical analysis}

Continuous data are presented as mean \pm standard deviation and categorical data are presented as percentages. The Shapiro-Wilk test was used to evaluate the normal distribution of data. The Mann-Whitney $U$ test was used to compare two groups that did not show a normal distribution of data. Values obtained at different time points for the two groups were measured using the Wilcoxon test. Yate's chi-square correction was used to analyze cross tables. All statistical analyses were performed using the SPSS Statistics 21.0 program (IBM). A $p$ value of $<0.05$ was considered statistically significant.

\section{Results}

In all, 437 patients with CSU were evaluated. Of these, 305 were excluded because they did not meet the study eligibility criteria (Fig. 1). Thus, this study included 132 patients, of which $84(63.6 \%)$ were women and $48(36.4 \%)$ were men. The mean age was 39.2 \pm 10.7 years (range 18-75 years). Disease duration was $<1$ year in $42(31.8 \%)$ patients, 1 to $<5$ years in $74(56.1 \%)$ patients, 5 to $<10$ years in $11(8.3 \%)$ patients, and $\geq 10$ years in $5(3.8 \%)$ patients. Urticaria was accompanied by angioedema in $31.8 \%$ of patients. Dermographism was observed in $33.3 \%$, NSAID hypersensitivity was observed in $9.8 \%$, and a history of atopy was observed in $16.7 \%$. ASST positivity was observed in $65.9 \%$ of patients, and ANA positivity was observed in $4.5 \%$. The mean serum IgE level was $54.4 \pm$ $150.3 \mathrm{IU} / \mathrm{ml}$ (range 7.0-978.9 IU/ml). AntiT positivity was observed in $11.4 \%$, and AntiTPO positivity was observed in 9.8\% (Table 1).

The patients received the following treatments before receiving the omalizumab treatment: $\mathrm{H}_{1}$ antihistamine treatment in up to four times the licensed dose ( $100 \%$ of patients), steroid treatment $(62.1 \%)$, cyclosporine treatment $(14.4 \%)$, montelukast treatment $(0.8 \%)$, and other treatments such as narrow-band ultraviolet $\mathrm{B}$, dapsone, azathioprine, and colchicine (5.4\%; Table 1).

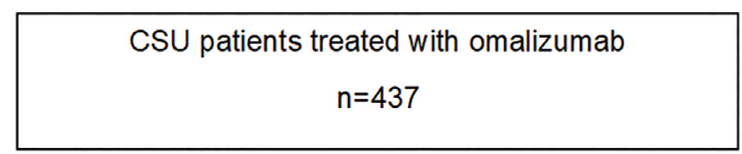

208 patients were not eligible:

- They did not use $300 \mathrm{mg} /$ month for 6 months

CSU patients treated with omalizumab for 6 months

$n=229$

97 patients were excluded

- Not recorded UAS7 and DLQI

132 CSU Patients were included study 
Seventy-eight $(59.1 \%)$ patients did not receive any other treatment with the omalizumab treatment. Omalizumab treatment was administered concurrently with the $\mathrm{H}_{1}$ antihistamine treatment in $53(40.1 \%)$ patients and with the cyclosporine treatment in one (0.8\%) patient (Table 1).

\section{Side effects}

No treatment-related side effects were reported by 118 (89.4\%) patients. However, one (o.8\%) and 13 (9.8\%) patients reported myalgia and nausea, respectively (Table 1 ).

\section{Treatment response}

The mean UAS7 value for the 132 patients was $30.5 \pm 12.4$ before omalizumab treatment and $1.5 \pm 4.06$ months after omalizumab treatment ( $p<0.001$; Table 1). Some patients responded to the treatment within only a few days. A significant difference was observed between the mean UAS7 value pre-treatment and the mean values 1 month and 2 months after treatment ( $p<0.001$; Table 2). However, no significant decrease in the mean UAS7 value was observed between the 2nd and 6th months after treatment (Table 2).

Of the 88 patients with severe disease based on the pre-treatment UAS7, 74 (84.1\%) had well-controlled disease, 13 (14.8\%) had mild disease, and a treatment response was not observed in one $(1.1 \%)$ patient after 6 months of treatment (Fig. 2, Table $3)$. Of the 26 patients with moderate disease before treatment, $23(88.5 \%)$ had well-controlled disease and two (7.7\%) had mild disease after 6 months of treatment. All four patients with mild disease before treatment had their disease fully controlled after 6 months of treatment (Fig. 2, Table 3).

A comparison of the demographic data, disease-related parameters, and laboratory data of the patients that showed $>90 \%$ improvement 1, 3, or 6 months after treatment with those that did not indicated no statistically significant differences among these patients. The mean DLQI score was $23.1 \pm 6.2$ before treatment and $3.6 \pm 3.6$ after treatment, and the difference was statistically significant $(p<0.001)$.

\section{Discussion}

The treatment of chronic urticaria aims to control symptoms and improve quality of life. Although clinical studies have reported the efficacy and safety of omalizumab in patients with CSU, only a few studies involving a large number of patients and enough information have reported real-world data (9-13). In Turkey, omalizumab treatment for patients with CSU has been reimbursable since April 2014 and is used as the third-line treatment for CSU, following the EAACI/GA²LEN/EDF/WAO guidelines (1).

The study presented here evaluated UAS7 values and observed a marked response 1 month and 2 months after treatment with omalizumab. Although patient responses to treatment were classified according to months, some patients showed a response within a few days of treatment. This is consistent with the results of clinical studies and with real-world data reported in the literature $(6,14-22)$. Omalizumab decreases free IgE levels on mast cell surfaces and downregulates FceR1 levels within 12 to 16 weeks $(23,24)$. Therefore, the early and rapid response of patients with CSU to omalizumab indicates the effectiveness of the treatment through various mechanisms. On the other hand, patients that show a poor response to omalizumab treatment should have their urticaria diagnosis re-evaluated.

Some studies have reported a complete response in $84.6 \%$ to

Table 1 | Demographic data and disease characteristics of the study patients.

\begin{tabular}{|c|c|}
\hline Variable & Value \\
\hline \multicolumn{2}{|l|}{ Sex } \\
\hline Female & $84(63.6 \%)$ \\
\hline Male & $48(36.4 \%)$ \\
\hline \multicolumn{2}{|l|}{ Age (years) } \\
\hline Median & $39.0(18-75)$ \\
\hline Mean \pm SD & $39.2 \pm 10.7$ \\
\hline \multicolumn{2}{|l|}{ Disease duration (years) } \\
\hline$<1$ & $42(31.8 \%)$ \\
\hline 1 to $<5$ & $74(56.1 \%)$ \\
\hline 5 to $<10$ & $11(8.3 \%)$ \\
\hline$\geq 10$ & $5(3.8 \%)$ \\
\hline \multicolumn{2}{|l|}{ History of } \\
\hline Angioedema & $42(31.8 \%)$ \\
\hline Dermographism & $44(33.3 \%)$ \\
\hline NSAID hypersensitivity & $13(9.8 \%)$ \\
\hline Atopy & $22(16.7 \%)$ \\
\hline \multicolumn{2}{|l|}{ ASST } \\
\hline Negative & 87 (28.8\%) \\
\hline Positive & $38(65.9 \%)$ \\
\hline Not recorded & $2(1.5 \%)$ \\
\hline \multicolumn{2}{|l|}{ ANA positivity } \\
\hline Negative & $110(83.3 \%)$ \\
\hline Positive & $6(4.5 \%)$ \\
\hline Not recorded & $16(12.1 \%)$ \\
\hline \multicolumn{2}{|l|}{ Serum IgE (IU/ml) } \\
\hline Recorded & $121.0(91.7 \%)$ \\
\hline Median & $65.0(7.0-978.0)$ \\
\hline Mean \pm SD & $54.4 \pm 150.3$ \\
\hline Not recorded & $11.0(8.3 \%)$ \\
\hline \multicolumn{2}{|l|}{ AntiT positivity } \\
\hline Negative & $112(84.8 \%)$ \\
\hline Positive & $15(11.4 \%)$ \\
\hline Not recorded & $5(3.7 \%)$ \\
\hline \multicolumn{2}{|l|}{ AntiTPO positivity } \\
\hline Negative & $114(86.4 \%)$ \\
\hline Positive & $13(9.8 \%)$ \\
\hline Not recorded & $5(3.8 \%)$ \\
\hline
\end{tabular}

Treatments administered before omalizumab

treatment

$\mathrm{H}_{1}$ antihistamines $\quad 132(100.0 \%)$

Systemic steroids $\quad 82(62.1 \%)$

Cyclosporine $19(14.4 \%)$

Montelukast

$9(6.8 \%)$

$\mathrm{H}_{2}$ antihistamine

$1(0.8 \%)$

Other

NB-UVB

$3(2.3 \%)$

Azathioprine

$2(1.5 \%)$

Dapsone

$1(0.8 \%)$

Colchicine

$1(0.8 \%)$

Treatments administered concurrently with

omalizumab treatment

None

$78(59.1 \%)$

$\mathrm{H}_{1}$ antihistamines

Cyclosporine

$53(40.1 \%)$

$1(0.8 \%)$

Side effect

None

$118(89.4 \%)$

Nausea

$13(9.8 \%)$

Myalgia

$1(0.8 \%)$

JAS7

Pre-treatment

$30.5 \pm 12.4$

Post-treatment

$1.5 \pm 4.0$

DLQI

Pre-treatment

Post-treatment

$23.1 \pm 6.2$

$3.6 \pm 3.6$

ANA $=$ anti-nuclear antibody, AntiT $=$ anti-thyroglobulin, AntiTPO $=$ anti-thyroid peroxidase, $A S S T=$ autologous serum skin test, $D L Q I=$ dermatology life quality index, NB-UVB = narrow-band ultraviolet B, NSAID = non-steroidal anti-inflammatory drugs, UAS7 = weekly urticarial activity score. 
Table 2 | Comparison of pre- and post-treatment UAS7 values using the Wilcoxon signed rank test.

\begin{tabular}{lcc}
\hline UAS7 $(n=132)$ & $\begin{array}{c}\text { Mean } \pm \text { standard deviation } \\
\text { Median }(\mathrm{Q} 1-\mathrm{Q} 3)\end{array}$ & $p$ \\
\hline Pre-treatment to month 1 post-treatment & $30.54 \pm 12.36$ & $<0.001$ \\
& $8.3 \pm 10.92$ & $<0.001$ \\
Months 1 to 2 post-treatment & $8.3 \pm 10.92$ & 0.900 \\
Months 2 to 3 post-treatment & $4.86 \pm 7.99$ & 0.250 \\
Months 3 to 4 post-treatment & $4.86 \pm 7.99$ & \\
Months 4 to 5 post-treatment & $4.11 \pm 7.48$ & 0.141 \\
Months 5 to 6 post-treatment & $3.11 \pm 7.48$ & \\
\end{tabular}

Table 3 | Changes in treatment response according to disease severity using a marginal homogeneity test.

\begin{tabular}{|c|c|c|c|c|c|}
\hline \multirow{2}{*}{ Pre-treatment UAS7 values } & \multicolumn{4}{|c|}{ UAS7 values at 6 months after treatment } & \multirow{2}{*}{$p$} \\
\hline & Well controlled & Mild disease & Moderate disease & Severe disease & \\
\hline Well controlled & $14(100.0 \%)$ & $0(0.0 \%)$ & $0(0.0 \%)$ & $0(0.0 \%)$ & \multirow{4}{*}{$<0.001$} \\
\hline Mild disease & $4(100.0 \%)$ & $0(0.0 \%)$ & $0(0.0 \%)$ & $0(0.0 \%)$ & \\
\hline Moderate disease & $23(88.5 \%)$ & $2(7.7 \%)$ & $1(3.8 \%)$ & $0(0.0 \%)$ & \\
\hline Severe disease & $74(84.1 \%)$ & $13(14.8 \%)$ & $0(0.0 \%)$ & $1(1.1 \%)$ & \\
\hline
\end{tabular}

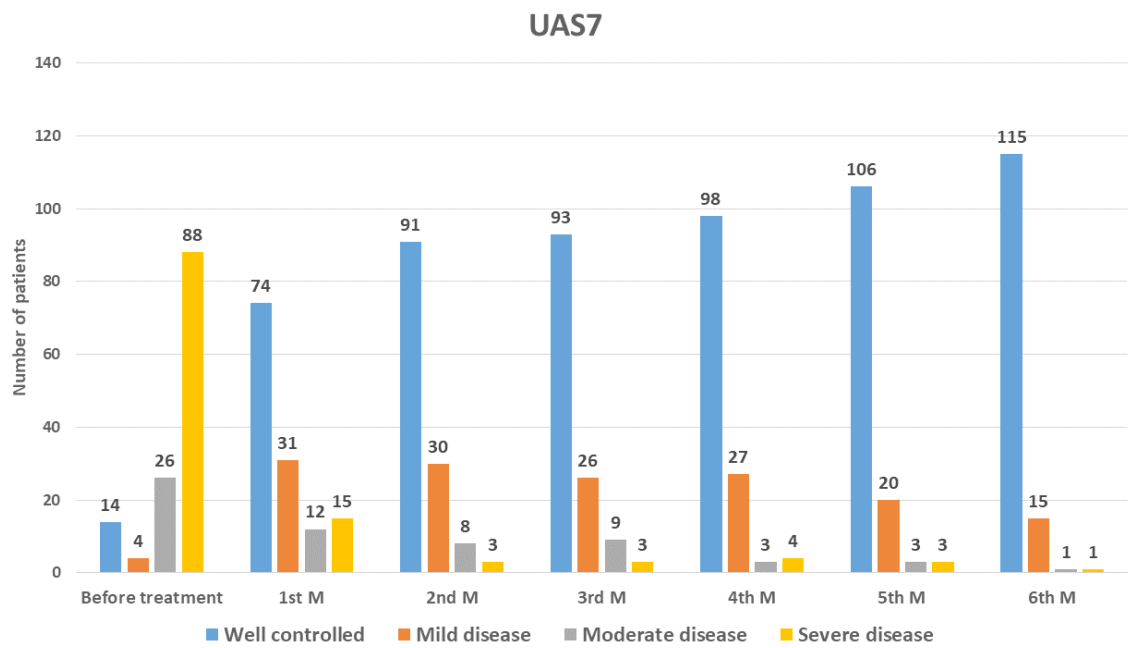

Figure 2 | Changes in the UAS7 score with treatment by month.

UAS7 = weekly urticarial activity score, $M=$ month.

$89.0 \%$ of patients $(6,12,15,16,25)$. In this study, $87.1 \%$ of patients exhibited well-controlled disease and $78.8 \%$ of patients showed $>$ 90\% improvement in UAS7 values 6 months after the omalizumab treatment. This is similar to results reported in studies performed in other countries.

CSU exerts a significant impact on quality of life (2). Patients with CSU display sleep disorders, fatigue, and unpredictable disease duration in addition to angioedema and itching (26-30). Thomsen et al. reported that patients with CSU that were resistant to $\mathrm{H}_{1}$ antihistamine treatment used healthcare services frequently and showed reduced quality of life (31). Maurer et al. reported a significant improvement in the quality of life of patients with CSU 12 weeks after omalizumab treatment, and Büyüköztürk et al. reported a significant improvement in the quality of life of patients with CSU 24 weeks after omalizumab treatment $(21,26)$. Savic et al. compared the effectiveness of omalizumab and cyclosporine treatments in patients with CSU and reported a significant improvement in the quality of life of patients receiving omalizumab treatment compared with that of patients receiving cyclosporine treatment (32). Consistent with those findings, the study presented here observed that DLQI scores markedly decreased and the quality of life of patients with CSU improved 6 months after omalizumab treatment. Moreover, 59.1\% of patients did not require any other treatment concurrent with the omalizumab treatment. Omalizumab treatment decreases the daily requirement of antihistamines and immunosuppressive drugs, which may exert systemic side effects in the majority of patients, indicating that decreasing the need for additional medication may also improve the quality of life of patients with CSU. Furthermore, Nettis et al. reported that omalizumab is a good option for preventing polypharmacy in elderly patients (33).

To date, the clinical or laboratory data required to determine the effectiveness of omalizumab treatment has not been defined (6, 34-36). A study by Ghazanfar et al. involving 154 patients with chronic urticaria that were treated with omalizumab reported that the absence of angioedema, a negative result on a histamine release test, advanced age, a history of short-term disease, and no history of immunosuppressant use were positive determinants of a response to omalizumab treatment (12). In the study presented here, no statistically significant association was observed between treatment response and demographic data, disease-related parameters, or laboratory data 6 months after treatment.

Clinical studies have reported that upper respiratory tract infection, headache, and skin and subcutaneous tissue disorders 
are the most common side effects of omalizumab treatment (37). Another study reported that the side-effect potential of omalizumab treatment was similar to that of placebo treatment (20). One clinical study reported a slight increase in sinusitis (4.9\% vs. $2.1 \%$ ), headache (6.1\% vs. $2.9 \%$ ), arthralgia ( $2.9 \%$ vs. $0.4 \%$ ), and cough $(2.2 \%$ vs. $1.2 \%)$ in patients receiving $300 \mathrm{mg}$ omalizumab compared with those receiving placebo (7). In the present study, $89.4 \%$ of omalizumab-treated patients did not report any side effects; however, nausea was reported in 13 patients and myalgia in one patient. The decreased incidence of side effects after omalizumab treatment in this study may be because of underreporting in the medical records of the study patients.

The study presented here is valuable because it includes a large number of patients with CSU that were treated with $300 \mathrm{mg} /$

\section{References}

1. Zuberbier T, Aberer W, Asero R, Bindslev-Jensen C, Brzoza Z, Canonica GW, et al. The EAACI/GA(2) LEN/EDF/WAO Guideline for the definition, classification, diagnosis, and management of urticaria: the 2013 revision and update. Allergy. 2014;69:868-7.

2. Koti I, Weller K, Makris M, Tiligada E, Psaltopoulou T, Papageorgiou C, et al. Disease activity only moderately correlates with quality of life impairment in patients with chronic spontaneous urticaria. Dermatology. 2013;226:371-9.

3. Weller K, Viehmann K, Bräutigam M, Krause K, Siebenhaar F, Zuberbier T, et al. Management of chronic spontaneous urticaria in real life-in accordance with the guidelines? A cross-sectional physician-based survey study. J Eur Acad Dermatol Venereol. 2013;27:43-50.

4. Wright JD, Chu HM, Huang CH, Ma C, Wen Chang T, Lim C. Structural and physical basis for anti-IgE therapy. Sci Rep. 2015;5:11581.

5. Beck LA, Marcotte GV, MacGlashan D, Togias A, Saini S. Omalizumab-induced reductions in mast cell Fc epsilon RI expression and function. J Allergy Clin Immunol. 2004;114:527-30.

6. Metz M, Ohanyan T, Church MK, Maurer M. Omalizumab is an effective and rapidly acting therapy in difficult-to-treat chronic urticaria: a retrospective clinical analysis. J Dermatol Sci. 2014:73:57-62.

7. Giménez-Arnau AM, Toubi E, Marsland AM, Maurer M. Clinical management of urticaria using omalizumab: the first licensed biological therapy available for chronic spontaneous urticaria. J Eur Acad Dermatol Venereol. 2016;30 Suppl 5: 25-32.

8. Oztürkcan S, Ermertcan AT, Eser E, Sahin MT. Cross validation of the Turkish version of dermatology life quality index. Int J Dermatol. 2006;45:1300-7.

9. Bernstein JA, Kavati A, Tharp MD, Ortiz B, MacDonald K, Denhaerynck K, Abraham I. Effectiveness of omalizumab in adolescent and adult patients with chronic idiopathic/spontaneous urticaria: a systematic review of "real-world" evidence. Expert Opin Biol Ther. 2018;18:425-48.

10. Denman S, Ford K, Toolan J, Mistry A, Corps C, Wood P, et al. Home self-administration of omalizumab for chronic spontaneous urticaria. Br J Dermatol. 2016; 175:1405-7.

11. Labrador-Horrillo M, Valero A, Velasco M, Jáuregui I, Sastre J, Bartra J, et al. Efficacy of omalizumab in chronic spontaneous urticaria refractory to conventional therapy: analysis of 110 patients in real-life practice. Expert Opin Biol Ther. 2013;13:1225-8.

12. Ghazanfar MN, Sand C, Thomsen SF. Effectiveness and safety of omalizumab in chronic spontaneous or inducible urticaria: evaluation of 154 patients. $\mathrm{Br}$ J Dermatology. 2016;175:404-6.

13. Vadasz Z, Tal Y, Rotem M, Shichter-Confino V, Mahlab-Guri K, Graif Y, et al. Omalizumab for severe chronic spontaneous urticaria: real-life experiences of 280 patients. J Allergy Clin Immunol Pract. 2017;5:1743-5.

14. Metz M, Ohanyan T, Church MK, Maurer M. Retreatment with omalizumab results in rapid remission in chronic spontaneous and inducible urticaria. JAMA Dermatol. 2014;150:288-90.

15. Rottem M, Segal R, Kivity S, Shamshines L, Graif Y, Shalit M, et al. Omalizumab therapy for chronic spontaneous urticaria: the Israeli experience. Isr Med Assoc J. 2014;16:487-90.

16. Saini S, Rosen KE, Hsieh HJ, Wong DA, Conner E, Kaplan A, et al. A randomized, placebo- controlled, dose-ranging study of single-dose omalizumab in patients with $\mathrm{H} 1$-antihistamine-refractory chronic idiopathic urticaria. J Allergy Clin Immunol. 2011;128:567-73.e1.

17. Wieder S, Maurer M, Lebwohl M. Treatment of severely recalcitrant chronic spontaneous urticaria: a discussion of relevant issues. Am J Clin Dermatol. 2015;16:19-26. month of omalizumab for 6 months, along with their detailed demographic and clinical data and UAS7 and DLQI values. However, the study had the following limitations: a) the number of patients continuing omalizumab treatment was unknown, b) changes in patient symptoms after the treatment was discontinued in the follow-up period were unclear, and c) the reasons for discontinuing treatment were not recorded.

In conclusion, these results indicate that treatment with 300 $\mathrm{mg} / \mathrm{month}$ of omalizumab for 6 months is effective and safe for treating Turkish patients with recalcitrant CSU. Moreover, treatment efficacy was observed within the first 2 months after treatment in most patients. However, no significant association was observed between omalizumab treatment effectiveness and patient characteristics or disease-related parameters.
18. Młynek A, Zalewska-Janowska A, Martus P, Staubach P, Zuberbier T, Maurer M. How to assess disease activity in patients with chronic urticaria? Allergy. 2008; 63:777-80.

19. Sussman G, Hébert J, Barron C, Bian J, Caron-Guay RM, Laflamme S, et al. Reallife experiences with omalizumab for the treatment of chronic urticaria. Ann Allergy Asthma Immunol. 2014;112:170-4.

20. Zhao ZT, Ji CM, Yu WJ, Meng L, Hawro T, Wei JF, et al. Omalizumab for the treatment of chronic spontaneous urticaria: a meta-analysis of randomized clinical trials. J Allergy Clin Immunol. 2016;137:1742-50.

21. Maurer M, Rosén K, Hsieh HJ, Saini S, Grattan C, Gimenéz-Arnau A, et al. Omalizumab for the treatment of chronic idiopathic or spontaneous urticaria. N Engl J Med. 2013;368:924-35

22. Maurer M, Altrichter S, Bieber T, Biedermann T, Bräutigam M, Seyfried S, et al. Efficacy and safety of omalizumab in patients with chronic urticaria who exhibit IgE against thyroperoxidase. J Allergy Clin Immunol. 2011;128:202-9.

23. Eckman JA, Sterba PM, Kelly D, Alexander V, Liu MC, Bochner BS, et al. Effects of omalizumab on basophil and mast cell responses using an intranasal cat allergen challenge. J Allergy Clin Immunol. 2010;125:889-95.

24. Beck LA, Marcotte GV, MacGlashan D, Togias A, Saini S. Omalizumab-induced reductions in mast cell Fc epsilon RI expression and function. J Allergy Clin Immunol. 2004;114:527-30.

25. Ensina LF, Valle SO, Juliani AP, Galeane M, Vieira dos Santos R, Arruda LK, et al. Omalizumab in chronic spontaneous urticaria: a Brazilian real-life experience. Int Arch Allergy Immunol. 2016;169:121-4.

26. Büyüköztürk $S$, Gelincik $A$, Demirtürk $M$, Kocaturk $E$, Colakoğlu B, Dal $M$. Omalizumab markedly improves urticaria activity scores and quality of life scores in chronic spontaneous urticaria patients: a real life survey. J Dermatol. 2012;39:439-42.

27. Maurer M, Weller K, Bindslev-Jensen C, Giménez-Arnau A, Bousquet PJ, Bousquet J, et al. Unmet clinical needs in chronic spontaneous urticaria. A GA2LEN task force report. Allergy. 2011;66:317-30.

28. Baiardini I, Giardini A, Pasquali M, Dignetti P, Guerra L, Specchia C, et al. Quality of life and patients' satisfaction in chronic urticaria and respiratory allergy. Allergy. 2003;58:621-3.

29. Lennox RD, Leahy MJ. Validation of the Dermatology Life Quality Index as an outcome measure for urticaria-related quality of life. Ann Allergy Asthma Immunol. 2004;93:142-6.

30. Grob JJ, Revuz J, Ortonne JP, Auquier P, Lorette G. Comparative study of the impact of chronic urticaria, psoriasis and atopic dermatitis on the quality of life. $\mathrm{Br}$ J Dermatol. 2005;152:289-95.

31. Thomsen SF, Pritzier EC, Anderson CD, Vaugelade-Baust N, Dodge R, Dahlborn $A K$, et al. Chronic urticaria in the real-life clinical practice setting in Sweden, Norway and Denmark: baseline results from the non-interventional multicentre AWARE study. J Eur Acad Dermatol Venereol. 2017;31:1048-55.

32. Savic S, Marsland A, McKay D, Ardern-Jones MR, Leslie T, Somenzi O, et al. Retrospective case note review of chronic spontaneous urticaria outcomes and adverse effects in patients treated with omalizumab or ciclosporin in UK secondary care. Allergy Asthma Clin Immunol. 2015;11:21.

33. Nettis E, Cegolon L, Di Leo E, Canonica WG, Detoraki A; Italian OCUReL Study Group. Omalizumab in elderly patients with chronic spontaneous urticaria: an Italian real-life experience. Ann Allergy Asthma Immunol. 2018;120:318-23.

34. Viswanathan RK, Moss MH, Mathur SK. Retrospective analysis of the efficacy of omalizumab in chronic refractory urticaria. Allergy Asthma Proc. 2013;34:44652. 
35. Kaplan AP, Joseph K, Maykut RJ, Geba GP, Zeldin RK. Treatment of chronic autoimmune urticaria with omalizumab. J Allergy Clin Immunol. 2008;122:569-73.

36. Ferrer M, Gamboa P, Sanz ML, Goikoetxea MJ, Cabrera-Freitag P, Javaloyes G, et al. Omalizumab is effective in nonautoimmune urticaria. J Allergy Clin Immunol. 2011;127:1300-2.
37. Casale TB, Bernstein JA, Maurer M, Saini SS, Trzaskoma B, Chen H, et al. Similar efficacy with omalizumab in chronic idiopathic/spontaneous urticaria despite different background therapy. J Allergy Clin Immunol Pract. 2015;3:743-50. 